\title{
Index to Volume 7
}

BARKMEIER, J Periodic attractors as a result of diffusion, 319

Bergelson, V Weakly mixıng PET, 337

BERNHARDT, $C$ The ordenng on permutations induced by continuous maps of the real line, 155

BLOCK, L AND HART, D Orbit types for maps of the interval, 161

BRIN, M AND KIFER, YU Dynamics of Markov chains and stable manifolds for random diffeomorph1sms, 351

CASDAgli, $M \quad$ Penodic orbits for dissipative twist maps, 167

DE CONCINI, C AND JOHNSON, R A The algebraic-geometric AKNS potentials, 1

Dumortier, F, Roussarie, R AND Sotomayor, J Genenc 3-parameter familes of vector fields on the plane, unfolding a singularity with nilpotent linear part The cusp case of codimension 3, 375

ELLIS, R Topological dynamics and ergodic theory, 25

ELTON, J H Ergodic theorem for iterated maps, 481

EMch, G G AND HoNG, S Time-like geodesic flows on Lorentz manifolds, 175

FELdman, J AND ORNSTEIN, D Semi-rigidity of horocycle fiows over compact surfaces of vanable negative curvature, 49

FLAMINIO, L An extension of Ratner's nigidity theorem to $n$-dimensional hyperbolic space, 73

FloER, A A refinement of the Conley index and an application to the stability of hyperbolic invariant sets, 93

FRIED, D Finitely presented dynamical systems, 489

GilmaN, R H Classes of linear automata, 105

GutierRez, C A counter-example to a $C^{2}$ closing lemma, 509

HANDELmaN, D Eventually positive matrices with rational eigenvectors, 193

Hart, D See Block, L and Hart, D

HAYDN, N T A On Gibbs and equilibrium states, 119

Hong, S See Emch, G G AND Hong, S

INNAMI, N A characterization of flat metrics on tori by ergodicity, 197

Johnson, R A See de Concini, C And Johnson, R A

JoNES, R L Necessary and sufficient conditions for a maximal ergodic theorem along subsequences, 203

DEL JUNCO, A On mınımal self-joinıngs in topologıcal dynamıcs, 211

DEL JUNCO, A AND RUDOLPH, D J A rank-one, rigid, simple, prime map, 229

DEL JUNCO, A AND RUDOLPH, D J On ergodic actıons whose self-joinıngs are graphs, 531

KifER, Yu See Brin, M AND KifER, Yu

KitChENS, B P Expansive dynamics on zero-dimensional groups, 249

KORNER, T Recurrence without uniform recurrence, 559

DE Melo, W and van Strien, S J Diffeomorphisms on surfaces with a finite number of moduli, 415

OliveirA, F On the generic existence of homoclinic points, 567

Ornstein, D See Feldman, J and Ornstein, D 
Pelikan, S and Slaminka, E E A bound for the fixed-point index of area-preserving homeomorph1sms on two-manifolds, 463

Pugh, C C The $C^{11}$ conclusions in Gromov's theory, 133

RAHE, M H AND Rudolph, D J Loose Bernoullicity is preserved under exponentiation by integrable functions, 263

RATNER, $M$ The rate of mixıng for geodesic and horocycle flows, 267

Roussarie, $\mathrm{R}$ See DUMORTIER, $\mathrm{F}$ et al

Rudolph, D J See DEl Junco, A AND Rudolph, D J (Two papers)

Rudolph, D J See RAHE, M H AND Rudolph, D J

Slaminka, E E See Pelikan, S and Slaminka, S

SOtomayor, J See DUMORTIER, F et al

SPATZIER, R J An example of an amenable action from geometry, 289

STOJANOV, L Generic properties of penodic reflecting rays, 597

van Strien, S J See de Melo, W and van Strien, S J

THOMAS, R F Entropy of expansive flows, 611

TOGAWA, Y A modulus of 3-dimensional vector fields, 295

TUNCEL, $S$ Markov measures determıne the zeta function, 303

URBANSKI, M Invariant subsets of expanding mappings of the circle, 647

VEECH, W A Boshernitzan's criterion for unique ergodicity of an interval exchange transformation, 149 